\title{
Preconceptional fasting of fathers alters serum glucose in offspring of mice
}

\author{
Lucy M. Anderson, Ph.D. ${ }^{\mathrm{a}, *}$, Lisa Riffle, B.S. ${ }^{\mathrm{b}}$, Ralph Wilson, B.S., M.T. ${ }^{\mathrm{c}}$, \\ Gregory S. Travlos, D.V.M. ${ }^{c}$, Mariusz S. Lubomirski, Ph.D. ${ }^{d}$, and W. Gregory Alvord, Ph.D. ${ }^{d}$ \\ ${ }^{a}$ Laboratory of Comparative Carcinogenesis, National Cancer Institute, Frederick, Maryland, USA \\ ${ }^{\text {b }}$ SAIC-Frederick, Frederick, Maryland, USA \\ ${ }^{\mathrm{c}}$ Laboratory of Experimental Pathology, National Institute of Environmental Health Sciences, Research Triangle Park, North Carolina, USA \\ ${ }^{\mathrm{d}}$ Data Management, Inc., Frederick, Maryland, USA
}

Manuscript received April 28, 2005; accepted September 30, 2005.

\begin{abstract}
Objective: Maternal nutrition has long-term effects on offspring characteristics. Similar effects mediated through fathers have not been tested.

Methods: Outbred Swiss male mice were fasted one or six times 1 to $4 \mathrm{wk}$ before mating. Offspring were killed at age intervals of 4 to $10 \mathrm{wk}$ and their sera were analyzed for glucose, corticosterone, and insulin-like growth factor-1. Statistical linear mixed effects models were used to determine treatment (paternal diet restriction versus control) differences and possible effects of covariates, including sex, litter membership, and litter size.

Results: Paternal food deprivation resulted in a consistent decrease in average serum glucose in male and female offspring. Significant changes in corticosterone and insulin-like growth factor-1 were found for some groups. The results indicated a male-mediated transgenerational effect on metabolism- and growth-related parameters, in particular glucose.

Conclusions: Effects of paternal nutritional experiences on offspring metabolism, if confirmed, would be novel and could have far-reaching implications in the context of transgenerational effects on chronic diseases. (C) 2006 Elsevier Inc. All rights reserved.
\end{abstract}

Keywords: $\quad$ Paternal fasting; Offspring; Glucose; Corticosterone; Insulin-like growth factor-1

An increasing body of information indicates that early life experiences may have long-lasting consequences on metabolism and chronic diseases [1-3]. In rodents, maternal undernutrition or glucocorticoid treatment produced offspring with symptoms reminiscent of the metabolic syndrome, including insulin resistance, as adults [2]. Paternal manipulations have also been found to affect metabolism in rodent offspring [4,5]. Thyroidectomy of male rats before mating led to enlarged pituitaries and thyroids, decreased thyroid-stimulating hormone, and several other changes in F1 offspring; an alteration in a thyrostat setpoint was suggested [6]. Treatment of male rodents with alloxan resulted in multigenerational transmission of pancreatic $\beta$-cell suppression and likelihood of diabetes development $[7,8]$. This

* Corresponding author. Tel.: +301-846-5600; fax: +301-846-5946.

E-mail address: andersol@mail.ncifcrf.gov (L.M. Anderson). alloxan effect was confirmed in rats by demonstration of progressive multigenerational loss of glucose tolerance [9-11]. In a study of a human population with documented variations in food supply [12], paternal experiences of famine during their childhood slow-growth periods resulted in protection of sons from cardiovascular death, and a surfeit of food for paternal grandfathers was associated with a significant increase in mortality from diabetes in their grandsons. The possibility thus raised, that paternal nutrition could influence metabolism in descendants, does not seem to have been studied in animal models.

\section{Materials and methods}

To examine effects of paternal food deprivation on offspring, male NIH NCr outbred Swiss mice ( 8 wk old) were subjected to 24-h fasts with free access to water. To mini- 
Table 1

Serum glucose in offspring after a single 24-h fasting of fathers

\begin{tabular}{lcc}
\hline & Fasted fathers & Control fathers \\
\hline $\begin{array}{l}\text { No. of litters } \\
\text { Offspring glucose (mg/dL) }\end{array}$ & 11 & 13 \\
Males* & $202.9 \pm 4.2(58)$ & $229.2 \pm 3.3(61)$ \\
& $P=0.0001$ & \\
Females* & $183.7 \pm 2.9(49)$ & $201.9 \pm 2.0(52)$ \\
& $P=0.0012$ & \\
\hline
\end{tabular}

* Number of offspring is presented within parentheses.

mize the effect of coincident variables, untreated controls were maintained in close parallel, including initial randomization into groups, side-by-side housing, killed at the same times, and concurrent sample analysis. All mice were fed a standard NIH-31 modified block diet (Purina Co., St. Louis, MO, USA) and were killed in a fed state except where indicated. For protocol 1, males were fasted once and then killed at the end of the fasting period to ascertain the immediate effects of fasting or mated 2 wk later to 8-wk-old untreated females. The 2-wk interval was chosen because of the observation that male-mediated transgenerational carcinogenesis effects are greatest after treatment at this time [13]. There were 20 males in each group and of these 11 of the fasted males and 13 of the controls produced surviving offspring. The offspring of these matings were weaned at 4 wk and killed at $10 \mathrm{wk}$ of age. For protocol 2, the males, 30 per group, were fasted six times for $24 \mathrm{~h}$ each time, twice per week for $3 \mathrm{wk}$, and then killed at the end of the final fast or mated $1 \mathrm{wk}$ later to 8 -wk-old untreated females. The 1 -wk interval was chosen to provide 2 wk between the midpoint of treatment of these males and mating. The numbers of surviving litters in each group are listed in Table 2. The offspring from protocol 2 were killed at 4, 6, 8, or 10 wk of age. Mice were killed and blood was collected by an approach that has been shown empirically to minimize stress-related changes in corticosterone [14]. Males were killed between 10 and $11 \mathrm{Am}$ and females between $11 \mathrm{Am}$ and $12 \mathrm{PM}$, when serum corticosterone levels were low and constant.

In neither experiment did fasting significantly affect average litter size or sex ratio. Offspring body weights after correction for litter size were not different, except for possible decreases in average body weights of female offspring of fasted fathers in experiment 2 at $4 \mathrm{wk}$ of age $(17.0 \pm 0.2$ versus $17.5 \pm 0.1 \mathrm{~g}, P=0.045)$ and $8 \mathrm{wk}$ of age $(21.2 \pm$ 0.2 versus $22.1 \pm 0.2 \mathrm{~g}, P=0.045$ ).

Sera of all offspring were analyzed for glucose, corticosterone, and insulin-like growth factor-1 (IGF-1) as described previously [14]. These endpoints were chosen because they were previously [14] shown to be affected by paternal treatment with chromium(III). The mechanism of action of the latter is thought to involve metabolic distortion due to its activity as a cofactor for glucose uptake by tissues. For clinical chemistry analyses, blood samples from mice were placed into tubes devoid of anticoagulant, allowed to 
clot at room temperature, and centrifuged and the serum was separated and stored frozen at $-70^{\circ} \mathrm{C}$ for analysis at a later date. Serum glucose analysis was performed by a hexokinase/glucose-6-phosphate dehydrogenase method using a Cobas Mira chemistry analyzer (Roche Diagnostic Systems, Montclair, NJ, USA) and commercially available reagents (Sigma Diagnostics, St. Louis, MO, USA). Serum corticosterone and IGF-1 concentrations were determined by ${ }^{125} \mathrm{I}$ radioimmunoassay techniques using an Apex automatic gamma counter (Micromedic Systems, Huntsville, AL, USA). Corticosterone was measured with using a solidphase assay (TKRC1 kit, Diagnostic Products Corp., Los Angeles, CA, USA), and a double-antibody procedure (DSL-2900 kit, Diagnostic Systems Laboratories, Webster, TX, USA) was employed for the determination of IGF-1.

All results are expressed as mean \pm standard error. Differences among measurements made on fathers were assessed with Student's $t$ test with Welch's correction, as appropriate. For statistical analysis of offspring data, linear mixed-effects models were used to determine treatment (paternal diet restriction versus control) differences and possible effects of covariates, including sex, litter membership, litter size, time-to-litter, and paternal weight on response measurements (offspring body weights and serum glucose, corticosterone, and IGF-1) [15-17]. In this approach the $n_{i}$-dimensional response vector for the $i$ th litter is expressed as:

$$
\begin{gathered}
y_{i}=X_{i} \beta+Z_{i} b_{i}+\epsilon_{i}, I=1 \ldots, M \\
b_{i} \sim N(0, \psi), \epsilon_{i} \sim N\left(0, \sigma^{2} I\right)
\end{gathered}
$$

where $X_{i}$ (of size $n_{i} \times p$ ) and $Z_{i}$ (of size $n_{i} \times q$ ) are known fixed effects and random effects regressor matrices, $\beta$ is the $p$-dimensional vector of fixed effects, $b_{i}$ is the $q$-dimensional vector of random effects, $\epsilon_{i}$ is the $n_{i}$-dimensional within-litter residual error vector with a spherical Gaussian distribution, $M$ is the number of litters, $N$ designates the normal distribution, $\psi$ is the covariance matrix, and $I$ is the identity matrix. The random effects $b_{i}$ were assumed to be independent for different litters and the within-litter errors $\epsilon_{i}$ were also assumed to be independent for different litters. This modeling approach recognizes two levels of random variation-1) among-litter variation, from the fathers to which the treatment conditions were applied; and 2) within-litter variation, from the pups on which the response measures were observed-and takes into account within-litter dependencies. Inferences regarding treatment differences were conducted by using among-litter restricted maximum likelihood variance estimates. $P<0.05$ was considered statistically significant. All probability values were two-sided.

\section{Results}

Fasting of male mice, of the same ages as those used for breeding, for $24 \mathrm{~h}$ resulted in an average $47 \%$ decrease in serum glucose and an average 10.5-fold increase in serum corticosterone (data not shown). Breeding performance was not affected. For both male and female offspring of the fathers that were fasted once, there were highly significant decreases in average serum glucose levels compared with those in controls at $10 \mathrm{wk}$ of age (Table 1). In male offspring of the fasted fathers, there was a possible small effect on serum corticosterone $(45.5 \pm 5.3$ versus $61.8 \pm 6.1$ $\mathrm{ng} / \mathrm{mL}$ for controls, $P=0.095)$ and on serum IGF-1 (692.3 \pm 24.1 versus $628.8 \pm 20.5 \mathrm{ng} / \mathrm{mL}$ for controls, $P=0.064$ ). For female offspring, serum corticosterone and IGF-1 levels were not altered by paternal fasting experience.

Males that were multiply-fasted as under protocol 2 and killed $24 \mathrm{~h}$ later showed an average $30 \%$ decrease in serum glucose and an average 5.7-fold increase in serum corticosterone compared with controls (not shown). They were thus somewhat less severely affected at the end of their treatment period than were males in protocol 1 (see above), which may indicate adaptation or may be related to increasing age and weight over these $3 \mathrm{wk}$. Data for the offspring from protocol 2 are presented in Table 2. Glucose did not differ between groups among male and female weanling 4-wk-old offspring. At 6 wk of age, however, there was a significant decrease in serum glucose in male and female offspring of fasted fathers compared with controls. This was especially prominent and significant in the male offspring. In 8-wk-old mice, glucose was significantly decreased in the serum of female offspring of fasted fathers. A more modest decrease in males fell short of statistical significance. For the 10-wk-old offspring, serum glucose in the male offspring of fasted fathers was lower than that in controls, with a high degree of statistical significance. Serum glucose was slightly lower in the female offspring of fasted fathers at this age, but the difference was not statistically significant.

With regard to serum corticosterone, the only marked and highly significant difference was in the males at age 10 wk, where offspring from fasted fathers showed approximately $30 \%$ lower corticosterone levels $(66.3 \pm 4.5 \mathrm{ng} / \mathrm{mL})$ compared with controls $(94.3 \pm 7.5 \mathrm{ng} / \mathrm{mL}, P=0.0054)$. This change was in the same direction and of the same magnitude as that observed in experiment 1 (see above). The reason for the different corticosterone values in the controls of the two experiments is not known at present. This observation requires repetition.

For IGF-1, there were highly significant differences in two comparisons of experiment 2 . In the male offspring at $10 \mathrm{wk}$, control IGF-1 levels were in the same range as those in the controls of experiment 1 . However, in experiment 2, IGF-1 levels were significantly lower in male offspring from fasted fathers $(457.9 \pm 11.3$ versus 545.9 $\pm 15.1 \mathrm{ng} / \mathrm{mL}$ in controls, $P=0.0006)$. In the female offspring at $8 \mathrm{wk}$, there was a nearly $25 \%$ higher IGF-1 level in those from fasted fathers $(571.6 \pm 15.9$ versus $405.5 \pm 11.1 \mathrm{ng} / \mathrm{mL}$ in controls, $P<0.0001)$. The reproducibility and meaningfulness of these changes will require further study. 


\section{Discussion}

The firmest, most convincing result of this study was decreased serum glucose in the 10-wk-old male offspring of the fasted fathers. This was seen, with a high degree of significance by conservative statistical testing, in these male offspring in both studies. Control glucose values for the males of this age were very similar for both studies. This appears to be a solid result. It is a remarkable finding considering the close regulation of serum glucose characteristic of animals. Although the differences were relatively small, $11 \%$ to $12 \%$, the published literature indicates that changes of this magnitude can be biologically meaningful. For example, genetic differences among rat strains, related to hypertension, included a significant $8 \%$ difference in serum glucose [18]. Risks of human cancers of several types were strongly associated with average increases in serum glucose of approximately $15 \%$ [19].

Decreased serum glucose in the male offspring was also observed at $6 \mathrm{wk}$ in experiment 2. More studies will be required to determine the meaning of the lesser effect at 8 wk. It is acknowledged that there was a significant difference in the baseline values at $10 \mathrm{wk}$ of age between the two studies for glucose in the females. The reasons for this difference are not known at present. All values are within accepted "normal" ranges for mice. The mouse strain is outbred and was chosen to maximize relevance to humans and to minimize the chance of discoveries that pertain to only one special mouse strain. However, some genetic differences may have been represented in the two studies. Different specific constituents of the open-formula diets are another possibility because the two studies were carried out more than a year apart. Because of the possibility, indeed likelihood, of fluctuations in metabolic parameters due to such causes, we took great care to design the experiments to minimize the impact of background noise. Fasted and control groups were maintained in close parallel, and offspring from each group were included with every scheduled kill. Further experiments will be required to confirm these findings and to discover the reasons for baseline variations.

The more pronounced and uniform effects on the male compared with the female offspring are consistent with those of other reports. Paternally mediated effects were most pronounced in male offspring for methadone [20] and cyclophosphamide [21] treatment of fathers.

If our findings are confirmed, they could have far-reaching implications for diseases such as obesity, diabetes, and cancer. They are consistent with reported effects of paternal and grand-paternal food abundance on disease risk in humans [12]. It is possible that paternal nutritional state is communicated to offspring to contribute to a predictive adaptive response [3], such as an altered glucostatic setpoint $[4,10]$. Our model could be used to study this possibility and underlying mechanisms, e.g., possible epigenetic reprogramming events in sperm [22].

\section{Acknowledgments}

The authors express appreciation to Rick Klabansky for data entry and to Yih-Horng Shiao and David Berrigan for critical reading of the manuscript and useful suggestions.

\section{References}

[1] Hales CN, Ozanne SE. For debate: fetal and early postnatal growth restriction lead to diabetes, the metabolic syndrome and renal failure. Diabetologia 2003;46:1013-9.

[2] Gluckman PD, Hanson MA. The developmental origins of the metabolic syndrome. Trends Endocrinol Metab 2004;15:183-7.

[3] Gluckman PD, Hanson MA. Living with the past: evolution, development, and patterns of disease. Science 2004;305:1733-6.

[4] Campbell JH, Perkins P. Transgenerational effects of drug and hormonal treatments in mammals: a review of observations and ideas. In: Boer GJ, Feenstra MG, Mirmiran M, Swaab DF, Van Haaren F, editors. Progress in brain research. Volume 73. Amsterdam: Elsevier Science; 1988, p. 535-52.

[5] Friedler G. Paternal exposures: impact on reproductive and developmental outcome. An overview. Pharmacol Biochem Behav 1996;55: 691-700.

[6] Bakke J, Lawrence NL, Bennett J, Robinson S. Endocrine syndromes produced by neonatal hyperthyroidism, hypothyroidism, or altered nutrition and effects seen in untreated progeny. In: Fisher DA, Burrow GN, editors. Perinatal thyroid physiology and disease. New York: Raven Press; 1975, p. 79-112.

[7] Okamoto K. Apparent transmittance of factors to offspring by animals with experimental diabetes. In: Liebell BS, Wrenshell GA, editors. On the nature and treatment of diabetes. Amsterdam: Excerpta Medica Foundation; 1965, p. 627-40.

[8] Ohno K. Electron microscopic study on beta cells of the islet of Langerhans in the rats under an experimentally induced prediabetic state. Kumamoto Med J 1969;22:41-53.

[9] Spergel G, Levy LJ, Golner MG. Glucose intolerance in the progeny of rats treated with single subdiabetogenic dose of alloxan. Metab Clin Exp 1975;20:401-23.

[10] Goldner MG, Spergel G. On the transmission of alloxan diabetes and other diabetogenic influences. Adv Metab Disorders 1972;6:57-72.

[11] Spergel G, Khan F, Goldner MG. Emergence of overt diabetes in offspring of rats with induced latent diabetes. Metabolism 1975;24: 1311-9.

[12] Kaati G, Bygren LO, Edvinsson S. Cardiovascular and diabetes mortality determined by nutrition during parents' and grandparents' slow growth period. Eur J Hum Genet 2002;10:682-8.

[13] Nomura T. Changed urethan and radiation response of the mouse germ cell to tumor induction. In: Severi L, editor. Tumours of early life in man and animals. Perugia: Perugia University Press; 1978, p. 873-91.

[14] Cheng RY-S, Alvord WG, Powell D, Kasprzak KS, Anderson LM. Increased serum corticosterone and glucose in offspring of chromium (III)-treated male mice. Environ Health Perspect 2002;110:801-4.

[15] Littell RC, Milliken GA, Stroup WW, Wolfinger RD. SAS system for mixed models. Cary, NC: SAS Institute; 1996.

[16] Millikin GA, Johnson DE. Analysis of messy data. Volume I: designed experiments. New York: Chapman \& Hall; 1992.

[17] Pinheiro JC, Bates DM. Mixed-effects models in S and S-Plus. New York: Springer-Verlag; 2000.

[18] Kloting I, Kovacs P, van den Brandt J. Quantitative trait loci for body weight, blood pressure, blood glucose, and serum lipids: linkage analysis with wild rats (Rattus norvegicus). Biochem Biophys Res Commun 2001;284:1126-33. 
[19] Jee SH, Ohrr H, Sull JW, Yun JE, Ji M, Samet JM. Fasting serum glucose level and cancer risk in Korean men and women. JAMA 2005;293:194-202.

[20] Joffe JM, Peruzovic M, Milkovic K. Progeny of male rats treated with methadone: physiological and behavioral effects. Mutat Res 1990; 229:201-11.
[21] Auroux M, Dulioust E, Selva J, Rince P. Cyclophosphamide in the $F_{0}$ male rat: physical and behavioral changes in three successive adult generations. Mutat Res 1990;229:189-200.

[22] Shiao Y-S, Crawford EB, Anderson LM, Ko K. Allele-specific germ cell epimutation in the spacer promoter of the $45 \mathrm{~S}$ ribosomal RNA gene after Cr(III) exposure. Toxicol Appl Pharmacol 2005;205:290-6. 